\title{
NOWE I KONWERGENTNE FORMY PRZEDSTAWIANIA TREŚCI AUDIOWIZUALNYCH. TELEWIZJA I YOUTUBE: PERSPEKTYWA PORÓWNAWCZA
}

\section{New and Convergent Forms of the Presentation of Audiovisual Content. Television and YouTube: Comparative Perspective}

Keywords: media convergence, YouTube, Television, media studies, genres

Contact: Uniwersytet Ślaskiw Katowicach; julia.zuz.piotrowska@gmail.com

\section{YouTube - telewizja XXI wieku?}

Podczas zeszłorocznej konferencji kończyłam mój referat stwierdzeniem, że YouTube jest - w pewnym sensie - telewizją XXI wieku. Choć podtrzymuję tę tezę, to uznałam, że wówczas nie została ona przeze mnie wystarczająco uzasadniona. Niniejszy tekst stanowi więc próbę rozwinięcia rozpoczętego wątku, zaś mój artykuł o językowej globalizacji na YouTube stanowi w takim ujęciu wstęp do poniższego tekstu.

Chciałabym skupić się tym razem na wątku konwergencji medialnej i na porównaniu YouTube'a i telewizji (w warunkach polskich), ze szczególnym uwzględnieniem podobieństw i różnic na poziomie gatunków i formy prezentacji treści.

\section{YouTube a telewizja w warunkach konwergencji mediów}

Telewizja zaliczana jest do mediów zimnych (McLuhan), czyli angażujących wiele zmysłów jednocześnie, przy jednoczesnym dostarczaniu treści nieprecyzyjnych i powierzchownych. W tym sensie znajduje się na tym samym biegunie, co YouTube. Jak się okazuje, nie jest to jedyny punkt wspólny dla tych mediów audiowizualnych.

Przede wszystkim należy podkreślić, że telewizja jest medium starszym od YouTube'a. Podczas gdy ekspansja pierwszego z wymienionych mediów przypadała mniej więcej na połowę XX wieku, o tyle serwis YouTube powstał w roku 2005, a więc prawie pół wieku później. Naturalną konsekwencją tego faktu jest więc to, że to 
YouTube naśladuje telewizję, a nie na odwrót ${ }^{1}$. To naśladownictwo jest natomiast rezultatem zjawiska konwergencji, do której nawiązuje między innymi Zbigniew Bauer na przykładzie gatunków dziennikarskich: ,gatunki dziennikarskie dzielą się zasadniczo na informacyjne i publicystyczne, jednak współcześnie powszechne jest zacieranie granic między nimi, zaś gatunki typowe np. dla prasy zostają wzbogacone elementami wizualności" (Bauer 2008: 255). Konwergencja - termin opisany przez amerykańskiego medioznawcę, Henry'ego Jenkinsa - to upodabnianie się jednych mediów do drugich, zazwyczaj mediów tradycyjnych do mediów internetowych, według poniższego wzoru.

\begin{tabular}{|l|l|}
\hline \multicolumn{1}{|c|}{ Gatunek w medium I } & \multicolumn{1}{c|}{ Gatunek w medium II } \\
\hline Audycja radiowa & Podcast \\
\hline Artykuł prasowy / felieton prasowy & Wpis na blogu \\
\hline Wywiad telewizyjny & $\begin{array}{l}\text { Rozmowa z zaproszonym gościem na } \\
\text { YouTube }\end{array}$ \\
\hline Audiotele & Q\&A \\
\hline
\end{tabular}

Tabela 1: Zestawienie przykładowych gatunków mediów tradycyjnych i nowych mediów w odniesieniu do zjawiska konwergencji

Rzecz jasna, konwergencja nie jest tym samym, co przeniesienie gatunku z jednego medium do drugiego. Twórcy zainspirowani określonym sposobem organizacji treści i formą, tworzą nową jakość w nowym medium. Podobieństwa mogą dotyczyć struktury, stylu, sposobów prezentacji, ale każde z tych kryteriów może podlegać modyfikacji. W tym sensie upodabnianie się nie jest tym samym, co adaptowanie się do nowych warunków. Pisze o tym zresztą sam Jenkins: „Nie mówimy już o rewolucji cyfrowej, która przewidywała, że stare media zostaną zastąpione nowymi. Teraz mówimy o konwergencji mediów, gdzie stare i nowe media wchodzą w coraz bardziej skomplikowane interakcje" (Jenkins 2007: 7).

YouTube jest medium audiowizualnym, wobec czego należy się spodziewać, że będzie czerpać wzorce z tradycyjnego, wcześniejszego medium audiowizualnego, jakim jest telewizja. Tak jest w istocie. Na YouTube można znaleźć wiele takich gatunków, które mają swój pierwowzór telewizyjny. Przykładami są wywiady, poradniki,

\footnotetext{
${ }^{1}$ Istnieją jednak wyjątki od tej reguły, opisane w dalszej części artykułu. 
programy popularnonaukowe, reportaże (na YouTube są to po prostu vlogi podróżnicze) itd. Mogą się różnić formą (np. kręcenie ,z ręki” vs. profesjonalna „operatorka”), sposobem przedstawiania (np. język ogólny vs. socjolekt młodzieżowy), typem nadawcy (np. starszy ekspert vs. młodszy ekspert) itd.

Konwergencja nie dotyczy jednak wyłącznie podobieństw gatunkowych. Niektórzy twórcy na YouTube „naśladują” telewizję w sposobie organizacji treści. Mają na przykład stałe godziny emitowania swoich treści - nawiązują więc oni do telewizyjnych ramówek, z odgórnie ustalonymi dniami i godzinami emisji.

Kolejnym dowodem na konwergencję między telewizją a YouTubem jest to, że znani twórcy młodszego medium często zapraszani są przez producentów telewizyjnych i reklamowych do udziału $w$ formatach emitowanych w telewizji. Na przykład Radosław Kotarski, założyciel i prezenter jutubowego ${ }^{2}$ kanału Polimaty reklamuje w telewizji bank Millenium; vlogerka Macademian Girl, czyli Tamara Gonzalez Perea, stała się prezenterką TVP2; Paulina Mikuła $\mathrm{z}$ kanału Mówiąc Inaczej była współprowadzącą program telewizyjny „Baking Bake Off - Ale ciacho!”. Oczywiście to tylko wybrane przykłady, ilustrujące pewną tendencję. Osobowości medialne z YouTube'a dobrze odnajdują się w formatach telewizyjnych i niemal natychmiast adaptują się do nowej formy prezentowania treści, nawet jeśli przekraczają granice „swojego” gatunku³.

Patrząc z perspektywy czasowej, z całą pewnością można powiedzieć, że YouTube $\mathrm{z}$ roku na rok coraz bardziej się profesjonalizuje i w ten sposób upodabnia się do telewizji. Spontaniczna twórczość, $\mathrm{z}$ biegiem lat, ulegała fundamentalnym przemianom. Filmiki nagrywane bez scenariusza, prezentowane audytorium w formie surowej (bez profesjonalnego montażu), produkowane bez chęci zysku to dziś znak przeszłości. Obecnie twórcy bazują na przygotowanym wcześniej scenariuszu, a prezentowane treści są zmontowane w sposób tak profesjonalny, jak w telewizji. Wielu jutuberów prowadzi nawet własną działalność gospodarczą i zatrudnia zespół współpracowników ${ }^{4}$, a więc tworzenie treści na platformę YouTube ma dziś wymiar zawodowy.

\footnotetext{
${ }^{2}$ Na potrzeby artykułu, w niektórych odmianach, zastosowałam formę ,jutubowy”, ,jutuber” itd.

3 Przywołana w przykładzie Paulina Mikuła z kanału „Mówiąc inaczej” na YouTube zajmuje się popularyzacją kultury języka polskiego, tymczasem w programie TVP „Baking Bake Off - Ale ciacho!” pełniła funkcję prowadzącej kulinarnego programu rozrywkowego.

${ }^{4}$ Dobrym przykładem jest Abstra, czyli przedsiębiorstwo zajmujące się produkcją treści wideo na YouTube, założona przez jutuberów z kanału Abstrachuje. W zaledwie kilka lat kanał rozwinął się na tyle, że stał się medialną firmą (pod którą działają już także inne kanały), współpracującą ze znanymi markami, w której rekrutuje się na stanowiska związane z montażem, scenopisarstwem, grafiką itd., por. www.abstra.tv/kariera.html (dostęp: 2020-04-14).
} 
Już sama nazwa jednostki medialnej, czyli „kanał”, może stanowić kluczowy trop $\mathrm{w}$ rozważaniach. Odbiorcy mediów mają do czynienia z kanałem telewizyjnym i kanałem na YouTube. Kanały stają się więc przekaźnikiem treści audiowizualnych i są one - w obu przypadkach - na tyle do siebie podobne, że nie ma nawet potrzeby tworzenia odrębnej nazwy. Co ciekawe, ten aspekt nie dotyczy tylko języka polskiego, bo w rzeczywistości anglojęzycznej jest to tak samo widoczne - słowo channel odnosi się zarówno do kanału telewizyjnego, jak i do kanału na YouTube.

Czy można sobie wyobrazić kierunek odwrotny, to znaczy upodabnianie się mediów tradycyjnych do mediów internetowych? To pytanie otwarte, bo nie dysponujemy jeszcze wystarczającymi dowodami na to, by miało się tak stać, niemniej nie jest to wykluczone 5 .

\section{Gatunkowość telewizyjna}

Autorzy „Popularnej encyklopedii mass mediów” (1999) zauważają, że gatunki dziennikarskie zasadniczo dzielą się na dwa rodzaje: informacyjne i publicystyczne. Natomiast w „Słowniku terminologii medialnej” (2006) czytamy także o gatunkach pogranicznych, realizujących jednocześnie komunikacyjną funkcję informacyjną i perswazyjną. To między innymi blogi reportażowe, talk-show czy debata. W miarę rozwoju mediów dochodzi do stopniowego rozmywania się „czystości gatunkowej”. Medioznawcy coraz częściej zastanawiają się natomiast, gdzie znajduje się granica między jednym a drugim gatunkiem, jakimi kryteriami kierować się przy definiowaniu danego gatunku, czy w ogóle mamy do czynienia z gatunkiem czy może z mniejszą jednostką kwalifikacyjną ${ }^{6}$. Do interesującego wniosku dochodzą autorzy „Encyklopedii wiedzy o prasie":

„Gatunki dziennikarskie jak wszystkie inne gatunki szeroko pojmowanego piśmiennictwa i sztuki są historycznie uwarunkowanymi wzorcami utrwalonymi w społecznej świadomości. Zespół wzorców akceptowanych przez nadawców (autorów, redakcje) i odbiorców (czytelników, słuchaczy, widzów) składa się na zjawisko świadomości gatunkowej, której stan podlega procesom nieustannych przemian" (Maślanka 1976: 90).

\footnotetext{
${ }^{5}$ Już teraz widać na przykład, że w telewizyjnych serwisach informacyjnych, na tzw. „paskach” coraz częściej pojawiają się hashtagi, czyli struktury znakowe, które dotychczas zarezerwowane były wyłącznie dla przestrzeni internetowej.

${ }^{6}$ Ten ostatni problem jest podejmowany m.in. w pracach: Loewe, I. Gatunki paratekstowe $w$ komunikacji medialnej. Katowice, 2007; Szymoniak, K. Między gazetą a Internetem - nowe gatunki dziennikarskie, paragatunki czy hybrydy? In: Język. Komunikacja. Informacja. Tom 3. 2008, s. 121-138; Barczyk, A. Internetowy talk-show - odmiana rodzajowa czy nowy gatunek? Charakterystyka programu $20 \mathrm{~m} 2$ Łukasza. Acta Universitatis Lodziensis. Folia Litteraria Polonica. 2003 (20/2), s. 255-270.
} 
W takim ujęciu gatunkowość uzależniona jest nie tyle od intencji nadawcy, co raczej od intuicji odbiorcy, który - na bazie swojej kompetencji - jest w stanie przyjąć określone konwencje i oddzielić to, co publicystyczne od tego, co informacyjne.

Telewizja jest medium szczególnym, w którym realizować mogą się nie tylko gatunki dziennikarskie (informacyjne i publicystyczne), ale także filmowe (dramat, western, komedia itd.) czy rozrywkowe (reality show, program śniadaniowy, makeover show itd.). Dochodzi również do wartościowania gatunków przez widzów (Godzic 2004), tzn. niektóre gatunki są „lepsze” lub „,bardziej prestiżowe” od innych.

To, co zwraca uwagę w kontekście gatunków telewizyjnych, to ich mnogość. Podobnie jak w przypadku gatunków dziennikarskich, także tutaj mamy do czynienia z „rozmyciem gatunkowym”, co zauważa Wiesław Godzic, pisząc o „nieczystości” genologicznej w telewizji. Medioznawca podaje też - za Jeremym Butlerem - trzy sposoby określania gatunku:

1. Prawdopodobna reakcja widzów na program.

2. Styl, czyli technika ukształtowania dźwięku i obrazu.

3. Wątek tematyczny i narracyjna struktura (Godzic 2004, za: Butler 1994: 296297).

To ostatnie stanowi swego rodzaju szkielet, na którym wspiera się gatunek. Godzic w taki sposób podsumowuje swoje rozważania: „Badanie gatunków telewizyjnych to $\mathrm{w}$ istocie badanie kultury i tworzącego ją społeczeństwa (...), więc musi ono być badaniem zorientowanym na zmienność i ciągłość (...); mysi być takim ponadto, które uzna, że gatunek jest interpretacyjnym filtrem, przez który (...) telewidz może wyprodukować znaczenie danego fragmentu tekstu telewizyjnego" (Godzic 2004: 25). Znów - podobnie jak w przypadku gatunków dziennikarskich - powraca więc wątek interpretacji odbiorcy.

\section{Gatunki telewizyjne a gatunki na YouTube}

Telewizja i YouTube wytwarzają swoje własne gatunki lub czerpią z innych gatunków medialnych. W tym sensie wpisują się więc w szerszą rzeczywistość powiązanych ze sobą niewidzialną genologiczną nicią form i struktur o konwencjonalnych ramach. $\mathrm{Na}$ przykład gatunek reportażu może realizować się zarówno w prasie, w radiu, jak i w telewizji. Oczywiście każde z tych mediów oferuje inne sposoby prezentowania tego gatunku, dysponuje różnymi komunikatami o charakterze werbalnym i niewerbalnym. Widać jednak, że konwergencja i gatunkowość są ze sobą ściśle powiązane, przynajmniej w niektórych przypadkach. 
YouTube oferuje szereg gatunków własnych, które byłyby trudne lub nawet niemożliwe do naśladowania $\mathrm{w}$ innych mediach, zwłaszcza tych tradycyjnych - nie tylko ze względu na ograniczenia formalne (np. obraz nie może być transmitowany przez radio), ale także konwencjonalne. Treści na YouTube mają bardziej „rozluźnioną” (bliższą naturalnej komunikacji bezpośredniej) formę przekazu, nastawione są na natychmiastową i niemal niezapośredniczoną interakcję z odbiorcami, nie muszą podlegać tym zasadom, które przez dziesięciolecia kształtowały się w mediach takich jak prasa, radio, czy telewizja. Trudno na przykład wyobrazić sobie, by w telewizji był zaprezentowany 20-minutowy materiał, w którym prezenter relacjonuje przebieg swojego dnia. Byłoby to niezgodne ze sztuką tworzenia treści telewizyjnych. Być może kiedyś się to zmieni, ale jeszcze nie teraz ${ }^{7}$.

Zarówno $\mathrm{w}$ telewizji, jak i na YouTube, obecne są gatunki charakterze rozrywkowym, informacyjno-publicystycznym i mieszanym (połączenie informacji, opinii, rozrywki) - ta klasyfikacja jest oczywiście dość skrótowa, bo nie oddaje wszystkich szczegółowych uwarunkowań, ale pokazuje pewną tendencję. Na przykładzie Polski widać to w poniższym zestawieniu.

\begin{tabular}{|c|c|c|}
\hline Typ gatunku medialnego & Telewizja & YouTube \\
\hline Rozrywkowy $^{8}$ & $\begin{array}{l}\text { „Mam talent”; } \\
\text { „Masterchef”; }\end{array}$ & $\begin{array}{l}\text { Red Lipstick Monter, } \\
\text { Loveandgreatshoes; } \\
\text { Szepcząca w Sieci ASMR; } \\
\text { GF Darwin }\end{array}$ \\
\hline $\begin{array}{l}\text { Informacyjno- } \\
\text { publicystyczny }\end{array}$ & $\begin{array}{l}\text { „Fakty”; „Wiadomości”; } \\
\text { „Sprawa dla reportera” }\end{array}$ & $\begin{array}{l}\text { Uwaga! Naukowy Bełkot; } \\
\text { Polimaty; Mama } \\
\text { i stetoskop; } 7 \text { metrów pod } \\
\text { ziemią; Krzysztof } \\
\text { Gonciarz; Max Kolonko - } \\
\text { MaxTV }\end{array}$ \\
\hline
\end{tabular}

\footnotetext{
${ }^{7}$ Tym bardziej interesujący będzie wówczas dla badaczy mediów kierunek konwergencji, bo wówczas to telewizja będzie ,uczyć się” od YouTube i będzie się coraz bardziej upodabniać do swojego nowszego odpowiednika.

${ }^{8}$ Gatunki (kolejność mieszana): reality show, cooking show, ASMR, beauty, vlog.

${ }^{9}$ Gatunki (kolejność mieszana): sserwis informacyjny, programy popularnonaukowe, reportaż; wywiad; felieton, vlog podróżniczy.
} 


\begin{tabular}{|l|l|l|}
\hline Mieszany $^{10}$ & $\begin{array}{l}\text { „Rolnik szuka żony”; } \\
\text { „Ziarno"; „Domisie”; } \\
\text { „Jeden z dziesięciu” }\end{array}$ & $\begin{array}{l}\text { Lekko Stronniczy; } \\
\text { GargamelVlog }\end{array}$ \\
\hline
\end{tabular}

Tabela 2: Typ gatunku medialnego w telewizji i na YouTube (nazwy programów i kanałów) - propozycja własna

Istotnym wątkiem w kontekście porównania telewizji i YouTube’a jest typ prezentowanego formatu. W telewizji warunkuje go tytuł programu, zaś na YouTube nazwa kanału. W tym sensie kanał, jako jednostka organizacji treści telewizyjnej, jest traktowana szerzej niż w przypadku kanału na YouTube. Na kanale telewizyjnym ogólnotematycznym (np. TVP, TVN, Polsat) prezentowane są zarówno gatunki rozrywkowe, informacyjne, jak i mieszane. Tymczasem kanały na YouTube, nawet te cieszące się największą oglądalnością (analogicznie do wspomnianych wyżej kanałów telewizyjnych ogólnotematycznych), mają wyraźny profil gatunkowy. Istnieją, rzecz jasna, wyjątki od tej reguły. Zdarzają się kanały na YouTube, które prezentują naprzemiennie gatunki rozrywkowe i informacyjne, ale jest to rzadkość.

W takim ujęciu całkowicie uzasadniona wydaje się tabela 2 , z porównaniem tytułów programów telewizyjnych i nazwą kanałów na YouTube.

\section{Sposoby organizacji czasu i emitowania treści}

Wspomniałam o tym, że konwergencja medialna obejmuje nie tylko te obszary, które związane są z treścią i formą, ale także ze sposobem organizacji czasu. Mam na myśli ramówkę telewizyjną, której odpowiednikiem jest - mniej formalny w założeniach porządek publikacji treści na YouTube.

Nowe medium upodabnia się do telewizji w tym sensie, że na niektórych kanałach filmiki wstawia się w konkretnym dniu, o konkretnej godzinie. Zasadę tę przyjmują takie popularne kanały jak: Lekko Stronniczy, Langusta na Palmie, Mówiąc inaczej, reZigiusz. Podobnie działa to w przypadku „lajwów” (ang. live - „na żywo”), czyli filmów emitowanych na YouTube na żywo, które są wcześniej zapowiadane za pośrednictwem mediów społecznościowych lub samej platformy YouTube ${ }^{11}$.

Należy jednak podkreślić, że upodabnianie się do telewizyjnej ramówki ma charakter raczej symboliczny. Z praktycznego punktu widzenia nie ma bowiem

\footnotetext{
${ }^{10}$ Gatunki (kolejność mieszana): commentery, program edukacyjny dla dzieci, teleturniej, program satyryczny.

${ }^{11}$ Wówczas taka treść oznaczana jest na liście subskrypcji jako „premiera”. Gdy kliknie się w ikonkę odtwarzania, pokazuje się widzom licznik z czasem pozostałym do rozpoczęcia materiału na żywo.
} 
Nowe i konwergentne formy przedstawiania treści audiowizualnych. Telewizja i YouTube: perspektywa porównawcza

konieczności takiego organizowania treści. Nie oznacza to jednak, że godzina publikacji filmu nie ma znaczenia - na podstawie algorytmów i statystyk twórca kanału jest w stanie określić, jakie godziny i dni gwarantują największe zasięgi, a tym samym największą oglądalność. Jest to bardziej zinformatyzowana wersja telewizyjnego prime time’u, czyli godzin największej oglądalności, w których emituje się najlepsze telewizyjne hity.

Trzeba też spojrzeć na telewizyjną ramówkę pod kątem ewentualnej nieprzewidywalności. Nie zawsze jest tak, że raz ustalona struktura czasowa nie ma prawa się zmienić. Warunkują to różnego rodzaju niespodziewane wydarzenia, katastrofy itd. Zachodzi niekiedy potrzeba szybkiej zmiany ramówki - na przykład w miejsce programu rozrywkowego pojawia się film dokumentalny o tematyce katastroficznej lub materiał wspomnieniowy o osobie lub grupie osób, które zginęły. Producenci telewizyjni, zakotwiczeni w „ramówkowej” i teoretycznie niezmiennej rzeczywistości, muszą więc wykazywać się elastycznością i reagować na dynamiczne zmiany. Gdyby tego nie robili, to widzowie czuliby niesmak, żal, rozdrażnienie, gdyby jakieś ustalone wcześniej treści, ulokowane w konkretnym, tragicznym kontekście, okazywały się ,nie na miejscu”.

Podobnie jest na YouTube, bo twórcy tego medium w dużym stopniu uzależnieni są od opinii swojego audytorium. To naturalna konsekwencja struktury mediów internetowych - komentujący i oceniający na bieżąco (kciuk w górę lub w dół) użytkownik - używając metafory politycznej - zyskuje status wyborcy. To on decyduje więc o popularności i tzw. zasięgach danego kanału. Nie chodzi więc wyłącznie o emocjonalność (tak jak w przypadku potencjalnie urażonych widzów, jak wyżej), ale o władzę.

Twórca na YouTube może podążać za ustalonym przez siebie schematem publikacji, ale prawie zawsze pyta odbiorców o zdanie - nie jest dla niego problemem nagranie filmu o tematyce, która w danym czasie najbardziej nurtuje widzów. Dopytuje w innych kanałach społecznościowych (np. na Instagramie), o czym ma nagrać kolejny odcinek itd. Może też szybko i spontanicznie reagować na sytuację na świecie ${ }^{12}$.

\footnotetext{
12 Przykład: filmik pt. „Nie jestem lekarzem ... ALE ... - teorie spiskowe, koronawirus i ludzie, którzy wiedzą lepiej ..." na kanale Uwaga! Naukowy Bełkot, nagrany - jak mówi twórca kanału, Dawid Myśliwiec spontanicznie, w reakcji na szerzącą się antynaukową dezinformację nt. koronawirusa. Myśliwiec zapowiada nawet, że prawdopodobnie usunie ten film po wygaśnięciu epidemii, bo nie pasuje on swoim wydźwiękiem do pozostałych treści na jego kanale, ze względu na zbyt duże natężenie emocjonalne.
} 


\section{Wartość edukacyjna telewizji i YouTube’a}

Istotną różnicą między telewizją a YouTubem jest to, że w przypadku tego pierwszego medium przekaz jest narzucony, a w przypadku drugiego - mamy do czynienia z demokratyzacją przekazu. Oznacza to, że telewizja dużo wolniej i mniej rewolucyjnie reaguje na preferencje widzów. Jest to w głównej mierze uzależnione od czynników technicznych, bo żeby określić stopień zainteresowania widzów danym formatem lub ofertą programową stacji, należy wykonać profesjonalne badania, a to wiąże się z dłuższym czasem oczekiwania na wyniki.

Tymczasem na YouTube takie analizy przebiegają znacznie szybciej popularność danego filmu lub kanału wyznaczają wyświetlenia, reakcje (kciuki w dół i kciuki w górę) oraz subskrypcje. Praktycznie z tygodnia na tydzień nadawca ma możliwość śledzenia trendów, a co za tym idzie - może na bieżąco reagować na potrzeby widzów. Zazwyczaj nadawca YouTube ma też dużo szerszy kanał kontaktu z widzami - może za pośrednictwem samego YouTube’a lub innych mediów społecznościowych odpowiadać na ich pytania i komentarze, tworzyć treści audiowizualne, które stanowią odpowiedź na najbardziej nurtujące widzów kwestie itd. Tym samym odbiorcy mają duży wpływ na treści, które dostarcza twórca, a co więcej mogą sami je tworzyć. Każdy może przecież założyć kanał na YouTube i zyskać popularność. Tymczasem dostęp do telewizji jest znacznie utrudniony. Sama jednorazowa obecność ,zwykłego człowieka” na małym ekranie to już nobilitacja świadczy o tym sam język, w którym funkcjonuje wyrażenie mieć parcie na szkło, które odnosi się właśnie do rzeczywistości telewizyjnej. Prezenterem, prowadzącym, dziennikarzem telewizyjnym, a nawet uczestnikiem show może być tylko wybrana, specjalnie wyselekcjonowana przez kierownictwo osoba. Obecność w telewizji ma więc wymiar instytucjonalny, formalny, a sam nadawca ustawiony jest w hierarchii komunikacyjnej w stosunku do odbiorców bardzo wysoko. Ta proporcja wygląda zupełnie inaczej w relacji jutuber - widzowie YouTube.

$\mathrm{Na}$ kształt i zawartość merytoryczną formatów audiowizualnych ma wpływ zarówno nadawca, jak i odbiorca, choć - jak już wspomniałam - różnie te relacje układają się w telewizji i na YouTube. Wolność twórcza, i dotyczy to zarówno nadawców telewizyjnych jak i internetowych, często skutkuje dominacją formatów czysto rozrywkowych nad formatami o charakterze edukacyjnym, czy nawet publicystycznym. Słowem - odprężenie i zabawienie widza jest warte dla nadawcy medialnego więcej niż skłonienie go do refleksji nad otaczającą rzeczywistością.

Tabloidyzacja, obniżenie jakości treści i konwergencja to zagadnienia, które ściśle się ze sobą łączą i przypomina o tym Agnieszka Całek: „Niewątpliwie (...) polska 
Nowe i konwergentne formy przedstawiania treści audiowizualnych. Telewizja i YouTube: perspektywa porównawcza

przestrzeń medialna ulega konwergencji. Jednoczenie jest też pod silnym wpływem tendencji tabloidyzacyjnych, co przejawi się zarówno w treści (obecność tematów sensacyjnych i kontrowersyjnych), jak i formie (zmniejszające się formaty gazet czy prymat obrazu nad tekstem). Obydwa zjawiska pozostają ze sobąw pewnej relacji” (Całek 2013: 311). Jest jednak nadzieja.

Dość przewrotne są same założenia dotyczące mediów. YouTube, jako medium społecznościowe, tworzone przez wszystkich dla wszystkich, ma z samego swojego założenia wymiar raczej rozrywkowy. Potrzeba atrakcyjnie spędzonego czasu byłaby więc czynnikiem motywującym do współuczestniczenia w tym medium, ponieważ człowiek, a już zwłaszcza człowiek wychowany przez telewizję, chętnie poszukuje treści rozrywkowych, a mniej informacyjnych ${ }^{13}$ lub edukacyjnych. O tych ludzkich skłonnościach pisze między innymi Neil Postman w książce „Zabawić się na śmierć” (1985): „Telewizja zastępuje (...) racjonalny dyskurs rozrywką” (Postman 2006: 7). Rzeczywiście, jeśli spojrzeć na pierwszą dziesiątkę najpopularniejszych kanałów na polskim YouTube ${ }^{14}$, to znajdują się tam wyłącznie takie o dominancie rozrywkowej. Na podium plasują się następujące kanały: Blowek (4 250000 substrybentów), Stuu (4 150 000 substrybentów), reZigiusz (3 810000 substrybentów). Jak się jednak okazuje, w serwisie YouTube znalazło się także miejsce dla treści popularnonaukowych, takich jak: Historia bez cenzury (1 060000 subskrybentów), emce (701 000 subskrybentów), Uwaga! Naukowy Bełkot (443 000 subskrybentów), Polimaty (601 000 subskrybentów), Nauka. To Lubię! (421 000 subskrybentów), Kasia Gandor (202 000 subskrybentów), Mówiąc Inaczej (434 000 subskrybentów), Arlena Witt (459 000 subskrybentów), Mama i stetoskop (121000 subskrybentów) itd. Są to kanały, prezentujące treści z dziedziny fizyki, matematyki, biologii, medycyny, historii i języka. Sposób prezentowania zagadnień jest zrozumiały dla odbiorców, a forma atrakcyjna, co przekłada się na ilość wyświetleń i subskrypcji. Takie kanały prowadzone są przez pasjonatów danej dyscypliny - absolwentów studiów magisterskich i doktorów, którzy zajmują się popularyzacją nauki. Na YouTube znaleźć można także kanały poświęcone edukacji finansowej, np. Jak oszczędzać pieniądze (75 700 subskrybentów), Marcin Iwuś (56 500 subskrybentów), VETO (388 000 subskrybentów), a także kulturze, czytelnictwu itd. Nie jest to więc wyłącznie rozrywka.

Gdyby przyjrzeć się ramówce, to $\mathrm{w}$ polskiej telewizji programy popularnonaukowe i edukacyjne stanowią obecnie mniejszość. Widz, który nie ma

\footnotetext{
${ }^{13}$ Te informacyjne coraz częściej same do niego „przychodzą”, czego dobrym przykładem jest News Feed na Facebooku, por. Vaidhyanathan, S. Antisocial Media. Jak Facebook oddala nas od siebie i zagraża demokracji. Tłum. Sosnowska, K., Mincer, W. Wydawnictwo W.A.B., 2018.

${ }^{14}$ Dane serwisu Apy News: www.apynews.pl/ranking-youtuberow (dostęp: 2020-04-25). Ilości subskrypcji podane w tym artykule to stan na dzień 25.04.2020.
} 
dostępu do kanałów specjalistycznych (to wiąże się z wykupieniem oferty na tzw. kablówkę), jest więc pozbawiony możliwości oglądania treści poświęconych konkretnym dziedzinom nauki.

W paśmie ogólnym dominuje rozrywka (reality show, seriale paradokumentalne), ewentualnie programy informacyjne. Programy przyrodnicze, dokumenty i programy popularyzujące naukę są emitowane raczej $\mathrm{w}$ godzinach wczesnoporannych lub późnowieczornych lub są przenoszone na kanały mniej popularne, jak na przykład TVP Historia (a i tam czasem panuje gatunkowy „bałagan"15). Tymczasem na YouTube to widz decyduje o tym, jakie kanały subskrybuje, a więc ma na swoim koncie na bieżąco aktualizowaną listę filmów od ulubionych twórców. Nie dotyczy go więc ,pasmo ogólne” - gdyby oczywiście przyrównać to do telewizji. Takim pasmem w przypadku YouTube’a byłaby karta „Na czasie", na której znajdują się najpopularniejsze w danym dniu w Polsce filmiki. Nie trzeba jednak w ogóle wchodzić na kartę „Na czasie”, bo domyślnym widokiem dla każdego użytkownika jest karta „Subskrypcje”, a więc treści wybrane i wyselekcjonowane przez niego samego. Tak więc nawet, jeśli kanały popularnonaukowe - w porównaniu z najpopularniejszymi kanałami YouTube w Polsce - cieszą się relatywnie małą popularnością, to jednak mają stałą i wierną grupę widzów, liczoną w kilkuset tysiącach osób. Treści nierozrywkowe mają więc szansę trafić do wszystkich zainteresowanych - inaczej wygląda to w telewizji, gdy widz jest „skazany” na treści ogólne, zwłaszcza gdy przeciętny odbiorca telewizyjny raczej nie ogląda telewizji wczesnym rankiem lub późnym wieczorem/w nocy.

\section{Wpływ na otaczającą rzeczywistość}

W obu typach mediów, zarówno w telewizji, jak i na YouTube, występują postaci znane lub aspirujące do tego, by były znane. W telewizji występują prezenterzy i celebryci, a na YouTube - prowadzący kanał i influencerzy. Wszystkie te grupy wpływają na widzów, kształtują ich percepcję, cieszą się zaufaniem i uznaniem lub - przeciwnie - są szykanowani i obśmiewani, a przynajmniej do momentu, gdy widz nie zrezygnuje z oglądania danego programu lub kanału. Generują jednak uwagę i nie pozostają obojętni.

Można więc uznać, że tacy nadawcy wpływają na rzeczywistość pozamedialną, prezentując określone wzorce i zapoznając widzów z konkretnymi treściami (obojętnie

\footnotetext{
15 Na TVP Historia prezentowane są nie tylko programy dokumentalne i popularnonaukowe o tematyce historycznej, ale także starsze odcinki teleturniejów, a w czasach stanu epidemii (od marca 2020 r.) program dla dzieci „Szkoła TVP”, przy czym prezentowane są tam wszystkie przedmioty lekcyjne, a nie tylko historia.
} 
czy są to treści tworzone na życzenie widzów czy narzucone przez producenta / wydawcę).

\section{Summary}

Both YouTube and television have a major impact on the social consumption of content. YouTube is an audiovisual medium, so it should be expected that it will draw patterns from the traditional, earlier audiovisual medium, which is television. On YouTube, one can find many such genres and ways of presenting content that has its television original. One medium resembles another, becoming - perhaps - a modern equivalent of its original. Creators inspired by a specific way of organizing content and form, create a new quality in a new medium. The similarities may relate to structure, style, presentation methods, but each of these criteria can be modified. So, becoming similar is not the same as adapting to new conditions.

\section{Literatura}

Barczyk, A. Internetowy talk-show - odmiana rodzajowa czy nowy gatunek? Charakterystyka programu $20 \mathrm{~m} 2$ Łukasza. Acta Universitatis Lodziensis. Folia Litteraria Polonica. 2013 (20/2), s. 255-270.

Bauer, Z. Dziennikarstwo wobec nowych mediów. Historia - teoria - praktyka. Lublin: Wydawnictwo Universitas, 2013.

Bauer, Z. Gatunki dziennikarskie. In: Bauer, Z., Chudziński, E. (eds.) Dziennikarstwo $i$ świat mediów. Nowa edycja. Kraków: Wydawnictwo Universitas, 2008, s. 143173.

Całek, A. Tabloidyzacja a konwergencja mediów - obraz wzajemnych zależności w polskim dyskursie publicznym. Analiza przypadku Tomasza Lisa. Środkowoeuropejskie Studia Polityczne. 2013 (2), s. 311-328.

Furman, W., Kaliszewski, A., Wolny-Zmorzyński, K. (eds.) Gatunki dziennikarskie. Teoria, praktyka, język. Warszawa: Wydawnictwa Akademickie i Profesjonalne, 2006.

Godzic, W. Telewizja i jej gatunki: po "Wielkim Bracie". Lublin: Wydawnictwo Universitas, 2004.

Jenkins, H. Kultura konwergencji. Zderzenie starych i nowych mediów. Warszawa: Wydawnictwa Akademickie i Profesjonalne, 2007. 
Skrzypaczek, J. (ed.) Popularna encyklopedia mass mediów. Poznań: Kurpisz, 1999.

Loewe, I. Gatunki paratekstowe w komunikacji medialnej. Katowice: Wydawnictwo Uniwersytetu Śląskiego, 2007.

Manovich, L. Język nowych mediów. Warszawa: Wydawnictwo Łośgraf, 2006.

Maślanka, J. (ed.) Encyklopedia wiedzy o prasie. Wrocław: Zakład Narodowy imienia Ossolińskich, 1976.

Pisarek, W. (ed.) Słownik terminologii medialnej. Kraków: Towarzystwo Autorów i Wydawców Prac Naukowych Universitas, 2006.

Postman, N. Zabawić się na śmierć: dyskurs publiczny w epoce show-businesu. Warszawa: MUZA, 2006.

Sasin M. Funkcje mediów regionalnych $w$ kształtowaniu zainteresowań kulturalnych młodziė̇y licealnej na przykładzie aglomeracji łódzkiej, rozprawa doktorska. Łódź, 2009.

Szymoniak, K. Między gazetą a Internetem - nowe gatunki dziennikarskie, paragatunki czy hybrydy? Język. Komunikacja. Informacja. 2008 (3), s. 121-138.

Vaidhyanathan, S. Antisocial Media. Jak Facebook oddala nas od siebie i zagraża demokracji. Tłum. Sosnowska, K., Mincer, W. Wydawnictwo W.A.B., 2018. 